http://aps.journals.ac.za

\title{
The Role of HIV/AIDS Prevention Campaigns on HIV- Related Behavioural Changes in Ibadan, Nigeria
}

\author{
L.A. Adeokun, O.A.Ladipo, P. Kanki, \\ G.E. Delano, A. Carrington \\ and C.O. Odimegwu ${ }^{1}$
}

\begin{abstract}
This study examined the impact of sources of AIDS education on HIV-related behavioural changes, and its implications for HIV prevention and service delivery in Nigeria. We analysed cross-sectional data obtained from a structured face-to-face interview with 1,373 respondents aged 15-50, who have ever had sex in Ibadan, Nigeria. Knowledge of HIV/AIDS, its route of transmission and prevention strategies was high. About $20 \%$ of the respondents were exposed to the AIDS prevention campaigns. A majority reported sexual behavioral changes, which included restriction of sex partners, use of condoms, sexual abstinence and avoidance of casual sex. Thirtynine percent took some steps to reduce risk of infection by avoiding transfusion with unscreened blood and testing for HIV status. Using multiple logistic regressions, the factors affecting the reported changes were identified. The application of health belief model shows that the model cannot wholly explain the changes in behavior. The role of female powerlessness in safer sex decision-making is noted. Despite the limitations of the study, the need for a sustained AIDS prevention campaign is stressed. The implications of the study for AIDS programs and research are highlighted.
\end{abstract}

\section{Introduction}

After more than a decade of lukewarm attitude to the AIDS epidemic by various levels of government in Nigeria, there is now an upsurge of initiatives to halt the spread of the disease. This is demonstrated by government's initiation of multisectoral strategies to promote access to information, prevention of mother-tochild transmission of HIV/AIDS and ensuring access to low-cost drugs such as nevirapine (USAID, 2001; JAAIDS, 2001; NACA, 2001). Component state governments in Nigeria have also joined in the intervention initiatives with funding support from donor agencies.

1 L.A. Adeokun is a Professor of Demography and Director of Operations Research and Evaluation of the Association for Family and Reproductive Health (ARFH), Ibadan, Nigeria; O.A. Ladipo is a Professor of Obstetrics and Gynecology and the President of ARFH; Phyllis Kanki is a Professor of Immunology and Infectious Diseases and Director of the AIDS Prevention in Nigeria (APIN) project of the Harvard School of Public Health, Boston, USA; G.E. Delano is the Vice-President of ARFH; A. Carrington was Associate Director of Government Relations and Community Programs in the APIN project, while Clifford Odimegwu was a Takemi Fellow in International Health of the Harvard School of Public Health and now directs a Graduate Program in Demography and Population Studies at the University of the Witwatersrand, South Africa. 
In the city of Ibadan, Oyo State, Nigeria, AIDS prevention activities to keep the public aware of personal risk and non-risk factors, the prophylactic behavior needed to keep down the rate of transmission were initiated to promote changes in those behavioral patterns that expose individuals to HIV risk (AwusaboAsare, 1999; Orubuloye and Oguntimehin, 1999). Studies have documented increased behavioral changes following specific communication interventions (National Research Council, 1996; Cleland 1995; Hogsborg and Aaby, 1992; NDHS, 1999; WHO, 1992; Allen et al., 1992a; Williams et al., 1992; Asamoah et al., 1994). Socio-demographic factors, which may hinder effective behavioral change, have also been noted (Caldwell et al., 1989) and the need for empowerment and community mobilization has been stressed (Aggleton, 1996; Parker, 1996a; 1996b).

With reported program impact on behavioral changes, the most important and useful question to those who plan and deliver reproductive health and HIV/AIDS prevention services is whether there is any benefit when HIV/AIDS prevention messages are disseminated through non-media sources apart from the traditional media approach. Studying the effect of exposure to various means of disseminating AIDS prevention messages will assist in identifying the usefulness or otherwise of these diverse strategies with a view to identifying where scarce resources should most profitably be allocated.

This study, therefore, examines the extent of behavioral changes and how various activities have influenced these changes. It also examines the usefulness of health belief model in the explanation of AIDS-related behavioral changes.

\section{AIDS Prevention Initiatives in Ibadan, Nigeria}

The Association for Family and Reproductive Health (ARFH), Ibadan, Nigeria, has been at the forefront of the campaign to improve reproductive health in the country. It is playing an increasing role to promote awareness of HIV/AIDS transmission routes and prevention. For twelve months, between May 2001 and May 2002, the Association utilized a number of strategies to disseminate information about HIV/AIDS transmission and prevention. The campaigns were carried out through the radio, television, print materials (posters, leaflets, newsletters, stickers), billboards, and poster competition among secondary schools. Other approaches included peer education, counseling, drama troupe targeted at youths and general population with sketches of pathways and lifestyles that lead to HIV infection and reinforcing the positive values and negotiating strategies that can lead to avoiding infection. This troupe toured a number of secondary schools in eight months. They also performed in most of the community outreaches. The drama title, HIV/AIDS is Dead, portrayed sexually active individuals as the vulnerable group but who can be empowered to wage war against the infection. Other activities included open market fora 
and carnival events involving market men and women, and their clients. There were also health talks organized in schools and other public places. Video shows on the disease were also shown.

In view of the rapid rate of HIV infection, its severe socioeconomic and demographic effects in affected populations and the predominant mode of transmission through heterosexual intercourse, a change of sexual behavior is regarded as the most important and appropriate prevention strategy (Ankrah et al., 1987; Ayiga et al., 1999; Rwabukwali, 1991). Behavior change is most important in populations where the prevalence of the infection is still low, as in Oyo State, Nigeria (with prevalence rate of 4.2), so that individuals can be empowered to protect themselves. The purpose of this paper, therefore, is to examine the impact of the ARFH's AIDS prevention initiatives in Ibadan in changing behaviors that predispose individuals to HIV risk.

\section{Theoretical Basis}

In recognition of the role of theory in social science research, this intervention was conducted within the health belief framework. This model addresses a person's perceptions of the threat of a health problem and the accompanying appraisal of a recommended behavior for preventing or managing the problem. (Rosenstock, 1974, 1988; Vanladingham et al., 1993; Bunnel, 1996). The model views behavioral change as a process involving changes in health beliefs. According to the original model, (Rosenstock, 1974), there are four components for a behavioral change to occur. First, a person must have a perception of personal susceptibility or risk to a health problem, in this case HIV/AIDS. Second, the problem must be seen as severe. Third, a person must weigh the benefits of changing a behavior and must perceive that the change option will be effective in protecting against the health threat. Finally, an individual must weigh the benefits against the perceived costs and perceived barriers to change. For a change to occur, the benefits must outweigh the costs. A variety of cues to action were thought to provide the trigger for action to occur (Uwalaka and Matsuo, 2002; Rosenstock, 1974; 1988; Vanladingham et al., 1993; Bunnel, 1996)

Rosenstock et al. (1974) have proposed the concept of self-efficacy in the model. Each of the four components represents continuous variables that are used in multiplicative relationship with the behavioral change outcome. If any of the variables is at zero, behavior change will not occur. If any of the variables increases, the outcome behavior is also likely to increase. This model has been used extensively in health research and has shown a reasonably predictive value for behavioral change. Nevertheless, the model has been criticized. According to VanLandingham et al. (1993), some of the specific components of the model are difficult to operationalize. The concept of "perceived barriers" that is those perceived obstacles to behavioral change, is difficult to define and identify. Any 
variable found to have negative association with health behavior could be a candidate for a perceived barrier. It would have been useful if the model specifies the types of barriers envisaged. Also distinguishing cause and effect in associations between perceived risk and behavior is very difficult especially when using a cross-sectional data. It also neglects the important aspects of the individual's social environment.

Additionally, Rosenstock et al. (1994) have found that no study has tested the model comprehensively. They posited that perceptions of benefits and barriers would be a more powerful predictor of behavioral change than perceived threat among those with high-perceived threat to HIV/AIDS. The ability of the health belief model to predict and explain HIV/AIDS-related behavior has been questioned given the lack of studies subjecting the model to formal tests. The shortcomings of the model are due to its conceptual limitations. It has also been acknowledged that the greater involvement of people living with HIV/AIDS (PLWHAs) in intervention activities will go a long way in reducing negative attitudes to PLWHA and will also convince individuals who have doubts about the disease (Lindan et al., 1997; UNAIDS, 2002).

\section{Methodology}

\section{Sample Recruitment and Selection}

This was a cross-sectional study involving the recruitment of study participants from the general population in Ibadan. Ibadan is a generic name for eleven different local government areas in Oyo State, Nigeria. There are two parts of Ibadan community. The city and its urban segments are called Ibadan Metropolis. It has five local government areas. The rural segment is the Ibadan Lesser City. The populations in these two areas are ethnically mixed, though the Yoruba constitute the predominant ethnic group.

A multi-stage probability sampling method was used for the selection of the samples. In each of the local government areas we estimated a sample size of 200 individuals selected randomly from the households. Each local government area was demarcated into eleven clusters such that 20 individuals were interviewed from each cluster. We used a network of trained interviewers to conduct face-to-face structured interviews with participants. Whereas female interviewers interviewed female respondents, males interviewed male respondents. The questionnaire included questions on socio-economic status, exposure to HIV/AIDS campaigns conducted by ARFH, and behavioral changes in response to the campaign. 
At the end, a total of 2,200 individuals ages 15-50+ were interviewed. After editing of the questionnaires, 94 were found to be improperly administered, and therefore were excluded from the analysis. Additional 733 questionnaires were dropped because the respondents claimed not to be sexually active. The present analysis is therefore limited to 1,373 individual responses from the general population who reported being sexually active and living in the communities where the campaigns were held.

\section{Survey Measures}

Respondents were asked about type of changes they have made to avoid HIV infection in response to the campaigns in the preceding months. The changes listed included having fewer sexual partners, using condoms with partners, sexual abstinence and not having casual sex. Respondents were also asked what other changes they have made to prevent or reduce the chances of infection from non-sexual sources of infection. These include avoiding sharing of unsterilized sharp instruments; transfusion of unscreened blood and testing for HIV. Respondents were further asked if they used condoms in their most recent sexual act; and whether they intend to use condoms in the future.

A summary variable measuring exposure to AIDS campaign was constructed from seven questions asking respondents if they had been exposed to messages on how to prevent HIV/AIDS through health talk, drama, video, training/counseling, radio and television or attended any meeting or discussion group for that purpose. Thus we had a variable which measures the number of times respondents attended HIV/AIDS campaign.

The seven sources of the campaigns were also grouped into two types namely the media-based sources (electronic and printed including the use of handbills, posters and leaflets, billboards) and the non-media sources which included information from personal contacts or one-on-one interaction with peer educators, teachers, friends, relatives, health workers, training and counseling programs. These two corresponded to the types of events that ARFH sponsored throughout the twelve months of the campaign.

The health belief model components were constructed from questions addressing each component of the model. Perception of susceptibility had two aspects. The first was constructed from question on how likely a respondent will be infected with STI/HIV/AIDS if he or she has sex with someone without using condom. The second aspect was related to the likelihood of infection if the individual had sex with spouse without condom. Perception of severity of AIDS was measured by asking the respondents whether the epidemic is increasing or otherwise. Benefit of action was measured by questions on what benefit respondents would have if they practiced forms of safer sex. Perception of barriers was measured by question on whether respondent feels satisfied using 
condoms or adopting any of the behavioral changes. Self-efficacy was also constructed from a series of questions on the respondent's ability to initiate safer sex negotiation with their partners or ability to take steps to protect themselves and even the actual use of condoms. Cues to action include the campaign exposure, awareness of people infected and affected by HIV/AIDS in the environment or neighborhood.

Inclusion of social and demographic variables to protect against spurious and masked relationships is always essential in the application of the health belief model that utilizes cross-sectional data. Background variables such as sex, age, marital status, education, religion, place of residence were included in the analysis. If the proponents of the health belief model are correct in their assertion that background factors will affect behavior only through the more proximate determinants of the model, then these background factors should be insignificant in the presence of the operationalized theoretical constructs. Employment status and income were excluded because of their correlation with educational level.

\section{Data Analysis}

Analyses were conducted using STATA Version 7.0 software. Chi-square tests were used to assess the differences. Multiple logistic regressions were calculated. Four models were developed, each to assess the contribution of the AIDS campaign and the health belief model to the reported behavioral changes. In addition to the variable representing number of campaigns attended, which was the main factor under study, key theoretically important background variables were included in the multivariate models. To build the multivariate logistic models, we conducted unvariate analyses to identify additional variables for inclusion in the final model. This enabled us to include only variables significant at $\mathrm{p}<0.05$. Education, age, religion, marital status, and place of residence were included.

\section{Results}

\section{Respondents Profile}

Table 1 indicates that more than half of the sample was men. More than onethird of the respondents were aged 20-29; $28 \%$ aged $30-39$, and $23 \%$ aged 40 and above.

Educationally, more than one-third of the respondents have completed secondary education and $21 \%$ had post-secondary education. Respondents belonging to the Islamic religion constitute 41 percent of the sample; more than $52 \%$ were Protestant and Pentecostal Christians. About two-thirds of the surveyed population was married. The sample was slightly more rural (56 \%) than urban $(44 \%)$. 


\section{Table 1: Percentage Distribution of Respondents' Socio-Economic Characteristics, Ibadan, Nigeria}

\begin{tabular}{lr}
\hline Characteristics & Percent $\mathbf{( N ~ = 1 3 7 3 ) ~}$ \\
\hline Sex & \\
Male & 53.4 \\
Female & 46.6 \\
Age & \\
$\quad<19$ years & 10.1 \\
$\quad 20-29$ & 39.2 \\
$\quad 30-39$ & 28.0 \\
$\quad 40+$ & 22.8 \\
Level of Education & \\
None & 7.8 \\
Primary Level & 20.3 \\
Secondary Level & 51.2 \\
Tertiary Level & 20.7 \\
Religion & \\
Catholic Mission & 4.7 \\
Protestant Mainline churches & 14.7 \\
Pentecostal Churches & 37.4 \\
Moslem & 40.9 \\
Others & 2.3 \\
Married & \\
Yes & 61.9 \\
No & 38.1 \\
Place of study & \\
Rural areas & 43.7 \\
Awareness of HIV/AIDS & 56.3 \\
\hline
\end{tabular}

At the time of the survey, most respondents (98.6\%) reported having heard of AIDS, its transmission and prevention strategies. This figure shows an increase over the rate obtained in 1999 by the Nigeria Demographic and Health Surveys, which put the level of awareness of HIV/AIDS in the South West at 89\%.

Table 2 shows that about $23 \%$ of all the respondents were exposed to the various AIDS campaigns mounted by ARFH in Ibadan during the intervention period. Health talk was the most widespread source of AIDS information, reaching 82 percent of those exposed to the interventions. This was followed by radio jingles $(76 \%)$, IEC materials $(75 \%)$, training and counseling $(64 \%)$, and television (58\%). Only $14 \%$ reported ever seeing an individual infected with HIV/ AIDS. 
Table 2: Percentage Distribution of Respondents' Exposure to Project Activities, Ibadan, Nigeria

\begin{tabular}{lc}
\hline Project Activities & \\
\hline Exposed to any of the ARFH AIDS Campaigns & 23.1 \\
Media of Exposure to ARFH AIDS Campaign & \\
Health talk & 82.0 \\
Radio jingles & 76.0 \\
IEC Materials & 75.0 \\
Training/counseling & 64.4 \\
Television & 58.0 \\
Drama & 54.3 \\
Video outreach & 52.4 \\
Knowledge of PLWHA & 14.0 \\
\hline
\end{tabular}

Exposure to the campaigns varied according to five of the social and demographic characteristics (Table 3). Exposure to the campaigns varies by the following factors sex, age, education, religion and marital status. There was no significant difference in exposure to AIDS campaigns by place of study, signifying lack of difference between the rural and urban areas of Ibadan in terms of exposure to HIV/AIDS campaigns.

Table 3: Percentage of Respondents who Reported Exposure to ARFH AIDS Campaign in the Preceding Twelve Months by Social and Economic Characteristics, Ibadan, Nigeria

\begin{tabular}{|c|c|}
\hline Characteristics & Percent \\
\hline \multicolumn{2}{|l|}{ Sex* } \\
\hline Male & 63.7 \\
\hline Female & 36.3 \\
\hline \multicolumn{2}{|l|}{$A g e^{*}$} \\
\hline$<19$ & 5.4 \\
\hline $20-29$ & 41.3 \\
\hline $30-39$ & 33.4 \\
\hline $40+$ & 19.9 \\
\hline \multicolumn{2}{|l|}{ Education* } \\
\hline None & 4.1 \\
\hline Primary & 11.7 \\
\hline Secondary & 49.2 \\
\hline Tertiary & 35.0 \\
\hline \multicolumn{2}{|l|}{ Religion* } \\
\hline Mainline Christian churches & 37.9 \\
\hline Evangelical Churches & 25.9 \\
\hline Moslem/others & 36.3 \\
\hline \multicolumn{2}{|l|}{ Married* } \\
\hline Yes & 63.4 \\
\hline No & 35.6 \\
\hline \multicolumn{2}{|l|}{ Place of survey } \\
\hline Urban & 47.0 \\
\hline Rural & 53.0 \\
\hline
\end{tabular}

- $\quad$ Differences across Categories at $p<0.001$. 


\section{AIDS Campaign and Behavioral Changes}

Reported behavioral changes were closely associated with some aspects of exposure to the ARFH-led AIDS prevention campaigns. Table 4 indicates that of those who reported exposure to these campaigns, $92.7 \%$ had adopted a specific sexual behavioral change. These included restriction of sexual partners $(47.6 \%)$, condom use $(47.6 \%)$, sexual abstinence $(30.9 \%)$ and avoiding casual sexual intercourse $(35.7 \%)$. In terms of risk reduction changes, about $39 \%$ had adopted some changes in their lifestyles to reduce the chances of infection through other sources of HIV transmission, including avoidance of transfusion with unscreened blood (36.9\%) and testing for HIV status (10.1\%).

Moreover, of those exposed to the campaigns and who had sex during the intervention period, $47 \%$ reported current use of condoms while $64 \%$ reported that they would intend to use condoms in their future sexual activity. There was significant difference in some behavioral patterns between the exposed and nonexposed groups.

Table 4: Percentage of Respondents Who Had Adopted Behavioral Changes, by Type of Exposure to the ARFH-Led AIDS Prevention Campaigns in the Preceding Twelve Months, Ibadan, Nigeria

\begin{tabular}{lrrr}
\hline Behavioral Changes & Total & \multicolumn{2}{c}{$\begin{array}{c}\text { Exposed to ARFH-led } \\
\text { AIDS campaigns }\end{array}$} \\
\cline { 3 - 4 } & & Yes & No \\
\hline Sexual behavioral change & 89.0 & 92.7 & $87.9^{*}$ \\
Restriction of sex partners & 51 & 47.6 & 52.3 \\
Use of condom & 49.7 & 47.6 & 50.3 \\
Sexual abstinence & 26.9 & 30.9 & $25.7^{*}$ \\
Avoid casual sex & 31.5 & 35.7 & $30.2^{*}$ \\
Risk reduction changes & & & \\
Avoid unscreened blood transfusion & 37.7 & 36.9 & 37.9 \\
Test for HIV & 6.2 & 10.1 & $6.0^{*}$ \\
Other changes & & & \\
Current use of condoms & 40.6 & 47.0 & $38.6^{*}$ \\
Intention to use condoms & 54.9 & 64.0 & $52.2^{*}$ \\
\hline * Significant Differences $\boldsymbol{a t} \quad \boldsymbol{p}<\mathbf{0 . 0 0 1}$ & & &
\end{tabular}

In the univariate analyses (Table 5), those with tertiary level of education were 6.8 times more likely to have adopted any behavioral change relative to the noneducated group. Those not in marital unions showed more likelihood of behavioral change than the married ones. Increasing exposure to AIDS campaign is more likely to lead to any behavioral change. For the variables associated with the health belief model, only five aspects were significant. Perception of self-efficacy has positive effect on any behavioral change, with those who claimed self-efficacy being 2.56 times more likely to adopt any 
behavioral change. Also perception of likelihood of infection if one had sex with anyone without the use of condom had a positive effect on the adoption of any behavioral change. Those with knowledge of someone infected or affected with HIV were 5.14 times more likely to have any behavioral change, signifying that having knowledge of someone with HIV/AIDS will influence individuals to adopt specific behavioral changes.

For any sexual behavioral change, the significant variables include number of exposure to AIDS campaigns (1.14, p<.040; 95\% CI: 1.00-1.29), females are less likely to adopt sexual behavioral change than males $(0.69, \mathrm{p}<0.035)$, not in marital union (3.76, $\mathrm{p}<0.000)$; perception of self-efficacy $(2.81, \mathrm{p}<0.000)$, perception of risk of infection with someone $(1.74 ; p<0.004)$, perception of risk of infection with spouse or sexual partner $(2.61 ; \mathrm{p}<0.000)$ and knowledge of PLWHA. Although the number of exposure to AIDS campaign has a negative effect on any risk reduction changes, it was shown that this had a positive effect on the testing for HIV status $(1.13, \mathrm{p}<0.036)$. Other significant variables in this association were education, knowledge of PLWHA and stigmatizing attitudes.

For current condom use among the sexually active, the significant variables were the number of AIDS campaigns, sex, age, marital status, perception of selfefficacy and risk perception. Intention to use condoms in the future also increased with increase in exposure to AIDS campaigns. The older age groups $(30-39,40+)$ were less likely to plan to use condoms in the future. Those not in marital unions were more likely to use condoms in the future. Self-efficacy, risk perception and PLWHA were other significant variables. As can be deduced from the four outcome variables of interest, exposure to the AIDS campaigns had significant positive effect on sexual behavioral changes, current condom use and intention to use condoms, and testing for HIV status.

\section{Multivariate Analysis}

The multivariate model compares respondents who adopted any sexual behavioral change, any risk reduction change, those who currently use condoms, and those who intend to use condom in future sexual activity, with those who did not, while controlling for number of exposures to AIDS campaign as well as social and demographic characteristics and health belief model components.

Sexual Behavioral Changes: Table 5 shows that the likelihood of the respondents adopting any sexual behavioral change, such as restriction of sexual partners, condom use, sexual abstinence and avoidance of casual sex, increases with the number of exposure to the AIDS campaign. Also those respondents who perceived themselves as being at risk of infection if they had sex with their spouses without the use of condoms were 2.72 times more likely to change their 
sexual behavior than those who did not have such a perception. Those not in marital unions were 3.50 times more likely to adopt any sexual behavioral change. Also respondents who felt self-efficacy (that is, those who thought they could initiate safer sex practices with their partners), and knowledge of PLWHA were more likely to adopt sexual behavioral changes. The model is significant with a high positive predictive value $(90 \%)$.

Risk Reduction Changes: Educated respondents were more likely to have adopted any risk reduction change than the non-educated ones. Knowledge of PLWHA increased the chances of risk reduction by the respondents, as those who were aware of individuals infected and affected by HIV/AIDS were more amenable to risk reduction changes than otherwise. Those who hold stigmatizing attitudes to HIV/AIDS were $33 \%$ less likely to reduce risk of exposure to infection.

Current Condom Use: As the number of AIDS campaigns increased, there was more likelihood that the general population would be using condom in sexual activity. Female respondents were $39 \%$ less likely to have used condoms in their sexual activity than male respondents. Those in age groups $20-29$ were 1.90 times more likely to be using condoms than the adolescents (aged $<19$ years). Those who were not in any marital union during the survey were more likely to be current users of condoms. Perception of self-efficacy and risk perception were other significant health belief model variables.

Intention to use condoms: It was expected that the campaigns would also encourage individuals who were not currently using condom to do so in future. The model shows that increasing the number of campaigns would increase respondents' willingness to use condoms in the future $(1.13 ; \mathrm{p}<0.003)$. The older age group $(40+)$ was less likely to have intention to use condoms. Perception of self-efficacy and perception of risk remained the other significant variables among all the health belief model variables.

Odds ratios were also constructed to assess the effect of exposure to the 7 specific campaign sources, social and demographic and health belief model variables on the four outcome variables. The seven sources of AIDS campaigns were collapsed into two namely media-based ones such as radio, television, printed materials and video shows, and the non-media type, which includes health talk, drama, training or counseling. 
Table 5: Odds Ratios from Logistic Regression Analyses Showing the Likelihood of HIV/AIDS-Related Behavioral Changes by Exposure to AIDS Campaigns, Socio-Demographic, and Health Belief Model Characteristics, Ibadan.

\begin{tabular}{|c|c|c|c|}
\hline Outcome/Independent Variables & $\begin{array}{r}\text { Univariate } \\
\text { OR (p-value) }\end{array}$ & $\begin{array}{r}\begin{array}{r}\text { Multivariate OR } \\
\text { (p-value) }\end{array} \\
\end{array}$ & $95 \% \mathrm{CI}$ \\
\hline \multicolumn{4}{|l|}{ A. Any Sexual Behavioral Change } \\
\hline Number of exposure to AIDS Campaigns & $1.14(\mathrm{p}<0.040)$ & 1.001 & \\
\hline \multicolumn{4}{|l|}{ Characteristics } \\
\hline Sex (female) & $0.69(\mathrm{p}<0.035)$ & 0.95 & \\
\hline Not in marital union & $3.76(\mathrm{p}<0.000)$ & $3.50(\mathrm{p}<0.001)$ & $1.71-7.47$ \\
\hline \multicolumn{4}{|l|}{ Health belief model } \\
\hline Self-efficacy & $2.81(\mathrm{p}<0.000)$ & $2.09(\mathrm{p}<0.045)$ & $1.02-4.33$ \\
\hline Perception of risk with anyone & $1.73(\mathrm{p}<0.004)$ & 0.93 & \\
\hline Perception of risk with spouse & $2.61(\mathrm{p}<0.000)$ & $2.72(\mathrm{p}<0.000)$ & $1.75-4.23$ \\
\hline Knowledge of PLWHA & $3.96(\mathrm{p}<0.000)$ & $3.06(\mathrm{p}<0.018)$ & $1.21-7.77$ \\
\hline \multicolumn{4}{|l|}{ B. Risk reduction changes } \\
\hline Number of exposure to AIDS campaigns & 0.99 & 0.94 & \\
\hline \multicolumn{4}{|l|}{ Characteristics } \\
\hline \multicolumn{4}{|l|}{ Education } \\
\hline None & 1.0 & 1.0 & 1.0 \\
\hline Primary & $1.97(\mathrm{p}<0.013)$ & 1.65 & \\
\hline Secondary & $2.11(\mathrm{p}<0.004)$ & $2.11(\mathrm{p}<0.015)$ & $1.15-3.87$ \\
\hline Tertiary & $3.25(\mathrm{p}<0.000)$ & $3.32(\mathrm{p}<0.000)$ & $1.74-6.31$ \\
\hline \multicolumn{4}{|l|}{ Health belief model } \\
\hline Knowledge of PLWHA & $1.95(\mathrm{p}<0.000)$ & $1.96(\mathrm{p}<0.001)$ & $1.34-2.86$ \\
\hline Stigmatizing attitudes & $0.70(\mathrm{p}<0.034)$ & $0.67(\mathrm{p}<0.038)$ & $0.46-0.97$ \\
\hline \multicolumn{4}{|l|}{ C. Current Condom use } \\
\hline \multicolumn{4}{|l|}{ Characteristics } \\
\hline Sex (female) & $0.55(\mathrm{p}<0.000)$ & $0.61(\mathrm{p}<0.000)$ & $0.466-0.795$ \\
\hline \multicolumn{4}{|l|}{ Age } \\
\hline$<19$ & 1.0 & 1.0 & 1.0 \\
\hline $20-29$ & 1.09 & $1.90(\mathrm{p}<0.034)$ & $1.05-3.43$ \\
\hline $30-39$ & $0.57(\mathrm{p}<0.033)$ & $\begin{array}{ll}15 & 1.58\end{array}$ & \\
\hline $40+$ & $0.37(\mathrm{p}<0.000)$ & 1.18 & \\
\hline Not in marital union & $3.59(\mathrm{p}<0.000)$ & $2.60(\mathrm{p}<0.000)$ & $1.83-3.70$ \\
\hline \multicolumn{4}{|l|}{ Health belief model } \\
\hline Self-efficacy & $8.34(\mathrm{p}<0.000)$ & $6.55(\mathrm{p}<0.000)$ & $2.29-9.32$ \\
\hline Perception of risk with anyone & $2.03(\mathrm{p}<0.000)$ & $1.54(\mathrm{p}<0.017)$ & $1.08-2.20$ \\
\hline \multicolumn{4}{|l|}{ D. Intention to Use condoms } \\
\hline Number of exposure to AIDS campaigns & $1.17(\mathrm{p}<0.000)$ & $1.13(\mathrm{p}<0.003)$ & $1.04-1.22$ \\
\hline \multicolumn{4}{|l|}{ Characteristics } \\
\hline \multicolumn{4}{|l|}{ Age } \\
\hline$<19$ & 1.0 & 1.0 & 1.0 \\
\hline $30-39$ & $0.46(\mathrm{p}<0.006)$ & 0.82 & \\
\hline $40+$ & $0.23(\mathrm{p}<0.000)$ & $0.46(\mathrm{p}<0.034)$ & $0.22-0.94$ \\
\hline & $2.71(\mathrm{p}<0.000)$ & $1.78(\mathrm{p}<0.002)$ & $1.24-2.55$ \\
\hline \multicolumn{4}{|l|}{ Health belief model } \\
\hline Self-efficacy & $7.65(\mathrm{p}<0.000)$ & $5.55(\mathrm{p}<0.000)$ & $2.52-12.16$ \\
\hline Perception of risk with anyone & $2.39(\mathrm{p}<0.000)$ & $1.86(\mathrm{p}<0.000)$ & $1.32-2.60$ \\
\hline Perception of risk with spouse & $1.35(\mathrm{p}<0.005)$ & 1.14 & \\
\hline
\end{tabular}

NB: Insignificant variables were excluded from the table where applicable. For instance, in one model education is excluded but included in another where it is significant. 
The univariate odd ratios show that exposure to AIDS campaigns through the media sources tend to be a major determinant of any sexual behavioral change and risk reduction changes. However the non-media based approach tended to influence current use of condoms than the media sources. Also those exposed to the AIDS campaigns were 1.70 more likely to be currently using condoms than those not exposed. Both sources are in the expected direction and significant in influencing the intention to use condoms in the future. (Table 6).

Controlling for the effects of social, demographic and health belief model variables, the multivariate analysis shows that the significant variables that influenced whether or not respondents adopted any sexual behavior the variables were unmarried status, perception of self-efficacy, perception of risk with spouse and knowledge of persons living with HIV/AIDS (PLWHA). Risk reduction changes were likely to occur among those with secondary and tertiary education, and those with knowledge of PLWHAs, while those exposed to AIDS prevention initiatives through non-media based sources were less likely to adopt risk reduction changes. 
Table 6: Odds Ratios (and 95\% Confidence Interval) from Univariate and Multivariate Analyses Assessing the Effects of Selected Characteristics on the Odd of HIV-Risk Behavioral Changes

\begin{tabular}{|c|c|c|c|}
\hline Outcome/Independent Variables & $\begin{array}{r}\text { Univariate OR } \\
\text { (P-value) }\end{array}$ & $\begin{array}{r}\text { Multivariate OR } \\
\text { (P-value) }\end{array}$ & $95 \% \mathrm{Cl}$ \\
\hline \multicolumn{4}{|l|}{ A. Sexual Behavioral Changes } \\
\hline Media exposure & $2.04(\mathrm{p}<0.022)$ & ns & \\
\hline Non-media exposure & 1.13 & ns & \\
\hline \multicolumn{4}{|l|}{ Characteristics } \\
\hline Unmarried & $2.33(\mathrm{p}<0.000)$ & $3.66(p<0.001)$ & $1.75-7.64$ \\
\hline \multicolumn{4}{|l|}{ Health Belief model variables } \\
\hline Perception of risk with spouse & $2.61(\mathrm{p}<0.000)$ & $2.72(\mathrm{p}<0.001)$ & $1.75-4.23$ \\
\hline Perception of self-efficacy & $2.81(\mathrm{p}<.000)$ & $2.09(\mathrm{p}<0.046)$ & $1.01-4.32$ \\
\hline Knowledge of PLWHA & $2.33(\mathrm{p}<0.000)$ & $3.11(\mathrm{p}<0.016)$ & $1.23-7.88$ \\
\hline \multicolumn{4}{|l|}{ B. Risk reduction changes } \\
\hline \multicolumn{4}{|l|}{ Characteristics } \\
\hline Media exposure & 1.03 & ns & \\
\hline Non-media exposure & 0.79 & $0.60(\mathrm{p}<0.046)$ & $.373-.990$ \\
\hline \multicolumn{4}{|l|}{ Characteristics } \\
\hline Primary & $1.97(\mathrm{p}<0.000)$ & ns & \\
\hline Secondary education & $2.11(\mathrm{p}<0.004)$ & $2.12(\mathrm{p}<0.015)$ & $1.15-3.88$ \\
\hline Tertiary education & $3.25(\mathrm{p}<0.000)$ & $3.33(\mathrm{p}<0.000)$ & $1.75-6.34$ \\
\hline \multicolumn{4}{|l|}{ Health belief models } \\
\hline Knowledge of PLWHA & 1.10 & $1.95(\mathrm{p}<0.001)$ & $1.33-2.86$ \\
\hline Stigmatizing attitudes & $0.71(\mathrm{p}<0.034)$ & $0.66(\mathrm{p}<0.055)$ & $.457-.970$ \\
\hline \multicolumn{4}{|l|}{ C. Current Use of Condoms } \\
\hline Media exposure & 1.22 & ns & \\
\hline Non-media exposure & $1.70(\mathrm{p}<0.013)$ & $1.70(\mathrm{p}<0.013)$ & $1.11-2.60$ \\
\hline \multicolumn{4}{|l|}{ Characteristics } \\
\hline Sex (Female) & $0.55(\mathrm{p}<0.000)$ & $0.61(\mathrm{p}<0.000)$ & $.46-.790$ \\
\hline Aged 20- 29 & 1.09 & $1.87(\mathrm{p}<0.037)$ & $1.03-3.39$ \\
\hline Age 30-39 & $0.57(\mathrm{p}<0.033)$ & ns & \\
\hline Age $40+$ & $0.37(\mathrm{p}<0.000)$ & ns & \\
\hline Unmarried & $3.59(\mathrm{p}<0.000)$ & $2.59(\mathrm{p}<0.000)$ & $1.82-3.68$ \\
\hline \multicolumn{4}{|l|}{ Health belief model variables } \\
\hline Perception of self-efficacy & $8.34(\mathrm{p}<0.000)$ & $6.62(\mathrm{p}<0.000)$ & $2.32-18.9$ \\
\hline Perception of risk with someone & $2.03(\mathrm{p}<0.000)$ & $1.52(\mathrm{p}<0.020)$ & $1.07-2.18$ \\
\hline \multicolumn{4}{|l|}{ D. Intention to use condoms } \\
\hline Media Exposure & $1.35(\mathrm{p}<0.057)$ & 1.18 & \\
\hline Non-media exposure & $1.80(\mathrm{p}<0.009)$ & $1.62(\mathrm{p}<0.055)$ & $0.90-2.68$ \\
\hline \multicolumn{4}{|l|}{ Characteristics } \\
\hline Age 30-39 & $0.46(\mathrm{p}<0.006)$ & & \\
\hline Age $40+$ & $0.23(\mathrm{p}<0.000)$ & $0.44(\mathrm{p}<0.028)$ & $.21-.916$ \\
\hline Unmarried & $2.71(\mathrm{p}<0.000)$ & $1.77(\mathrm{p}<0.002)$ & $1.23-2.53$ \\
\hline \multicolumn{4}{|l|}{ Health belief model variables } \\
\hline Perception of self-efficacy & $7.65(\mathrm{p}<0.000)$ & $5.65(\mathrm{p}<0.000)$ & $2.57-12.39$ \\
\hline Perception of risk with someone & $2.39(\mathrm{p}<0.000)$ & $1.83(\mathrm{p}<0.000)$ & $1.31-2.56$ \\
\hline
\end{tabular}




\section{Discussion and Conclusion}

The level of knowledge about HIV/AIDS among the general population in Oyo State, Nigeria was quite high. Other studies have shown similar result (NDHS, 1999). However, most respondents did not know that HIV could be transmitted from an infected mother to the child (8.2\%) while many do not see screening of pregnant women as a method to prevent HIV infection (2.3\%). Better knowledge about HIV/AIDS was associated with level of education as those with higher level showed a better knowledge than those with low level of education.

Majority of the respondents had taken specific steps to protect themselves from HIV infection through changes in sexual behavior (89\%) while $39 \%$ have also adopted risk reduction strategies or non-sexual behavioral changes. The type and pattern of change reflects the socioeconomic characteristics of the respondents. For example sexual behavioral changes vary by age, educational level, religion and IEC exposure of the respondents. Men reported more condom use with non-casual sex partners. Those with higher level of education demonstrated clear behavioral changes than the non-educated ones. In fact the higher the level of education, the more likely there were behavioral changes in response to the campaigns.

This study shows that women were less likely to make any behavioral change than men. This tends to confirm the reported powerlessness of female gender in reproductive decision-making (Worth, 1989; Gupta and Weiss, 1993; Varga, 1997). Worth (1989) found resistance to condoms among minority women in drug rehabilitation program to be the result of a combination of personal preferences and socio-cultural factors, and partner's objections to condoms. The idea of condom use conflicts with prevailing values about relationships, womanhood and family. Fundamental to women's enjoyment of sex was affirmation of trust and fidelity through unprotected sex, and fulfillment of family and gender roles through pregnancy and childbearing (Pivnick, 1993). Moreover, some women appeared unable to exert an influence over condom use through fear of rejection and stigmatization by partners. Such factors led women's sexual risk-taking - unprotected sex - to be characterized as a rational means of maintaining social and economic survival. (Sobo, 1995). Empowerment of women to negotiate sexual activity should form part of programs of AIDS prevention.

If the older age groups demonstrated willingness to adopt behavioral changes than the adolescents aged $<19$ years, this becomes a big challenge to reproductive health service providers. The youths constitute $45 \%$ of Nigeria's population. More effective programs should be designed to address the special needs of this population. Programs should target places where youths gather such as in schools, workshops etc. Their misconceptions and attitudes should be 
addressed. Alternatively, non-governmental organizations should have specific areas of specialization that is, concentrating on specific social group so that their programs can have stronger effect on that population. In either the univariate or multivariate models, there is no significant influence of religious affiliation observed.

The strong association between education and various behavioral changes suggest that efforts at promoting free education, which is a hallmark of the government in Oyo State, Nigeria, may facilitate risk reduction efforts for HIV/ AIDS. It also suggests that the educated group in the society can be used to disseminate the information about HIV/AIDS since these are the ones amenable to changes.

Usefulness of the Health Belief Model: Of the five components of the health belief model examined in the multivariate analyses, only three were strong predictors of sexual behavioral changes; two strongly predicted the chances of risk reduction changes, current use and intention to use condoms. The major health belief model predictors of behavioral change in Ibadan, South West Nigeria were perception of self-efficacy, perception of risk of infection and knowledge of PLWHA and exposure to AIDS campaign. Thus perception of self-efficacy, perception of susceptibility and cues to action (media publicity and influence of knowing someone with HIV/AIDS) were the critical health belief model components affecting behavioral change in this population

The non-media approach to AIDS campaign had strong effect on sexual behavioral change, current use of condoms (OR: 1.70; $\mathrm{p}<0.013$ ), intention to use condoms (OR: 1.62; $\mathrm{p}>0.055)$. However while media approach has the expected positive effect on the four outcome variables, the relationship is not significant in a multivariate model. This indicates that the use of media campaign alone cannot alone impact positively on behavioral changes.

\section{Implications of Findings to Research and Program Delivery}

The results of this study have some important implications.

1. Knowledge of HIV/AIDS is high. Majority of respondents were aware of the transmission routes and prevention strategies. However we did not find the translation of this knowledge into action, as many who knew of HIV/AIDS were not practicing safer sex as many as $59.2 \%$ of them reported non-use of condoms in the last sexual act. Among the married who were aware of AIDS routes and prevention, one-third used condom in the last sexual act while among those not in union $62 \%$ were using condoms and $48 \%$ intends to use condoms. This discrepancy is a major challenge to reproductive health programmers. Research should also be designed to explain the discrepancy or gap between knowledge and behavior in regard to HIV/AIDS. 
2. The dose-response effect is not strong as would be expected, though the result of the analysis shows that as the number of AIDS campaigns increases, the chances that individuals will adopt behavioral changes increased. The media approach had more effect on behavioral change in a univariate model. Controlling for socio-economic characteristics shows that non-media approach had more powerful influence. We recommend that the two types of channels could be utilized in campaigns but more meaningful result would be achieved if programmers scale the kind of activities they would want to implement. The fewer the activities, the better and more effective would be the impact. Embarking on seven different activities in a 12-month program must be an uphill task lacking proper coordination. This could be the reason why the impact of the multimedia campaign is not strong enough and in some cases statistically insignificant. The opportunity for innovative communication programs remains. Additional research is needed to determine how to meet information needs of the general population most effectively and how to provide a continuous flow of information that is lively and interesting. Behavioral change is a lengthy process requiring information and decisionmaking, and continued behavioral change requires regular reinforcement and renewed commitment. A 12-month AIDS campaign should not be expected to produce adequate support for current and consistent behavioral change.

3 . The only evaluation design that can provide information about the effect of the given intervention with any degree of certainty is an experimental evaluation in which eligible entities are randomly assigned to the experimental group that gets the treatment or the control group that does not get the treatment. Moreover, internal validity of this study could have been improved if greater control had been built into the design such as exposure to HIV educational materials outside the ARFH intentions, length of time that elapsed between the intervention and the survey, and concern over one's current health status.

4. Health belief model is a useful framework for designing change strategies as it helps to develop messages that are likely to persuade individuals to make healthy decisions. However the use of this model to measure stages of change process is a methodological fallacy not supported by literature. Better models that focus on stages of change would have been more meaningful. These include AIDS risk reduction model, which provides a framework for explaining and predicting the behavior change efforts of individuals (Catania et al 1990), and Stages of Change theory (Prochaska and Diclemente, 1986). We hope that the combination of these stage-based models will yield more valid data that is possible in dealing with complex behavioral phenomena. Since no model can explain or predict all aspects of health behavior, combining theoretical models can create stronger public health education programs.

Though the findings of this study cannot be attributed to the twelve months intervention activities in the City of Ibadan, Nigeria alone, it has shown at least 
that HIV/AIDS-related behavioral changes are taking place in the community. The change is a step ahead from earlier findings reported in the demographic surveys. The factors identified can be used to target groups for the prevention activities. Moreover, effective training programs should be designed to use more of the personal contact approach to reach out to the people. Evaluation of such activities should be done using standardized instruments at pre and post-test stages of the intervention.

\section{Limitations}

However this study has some important limitations. The cross-sectional design of the study limits its ability to specify the direction of causality between exposure to different AIDS prevention activities and the reported behavioral changes. Also the validity of self-reported sexual behavioral data is problematic. Since there is a high level of awareness of HIV/AIDS, its transmission and prevention, behavioral changes may be over-reported because most people know what to say or might have decided to give responses that would satisfy the interviewers. Also the data set does not permit us to investigate what was the behavioral pattern of the respondents prior to the study with a view to measuring the difference, which can be attributed to the intervention. It was not possible to control for the noise effect in this analysis. The specification of the model could be faulty because we did not have access to measures of the model. Lack of qualitative tools to explain an observed discrepancy is another problem in this study. In spite of the limitations, we feel the results are encouraging, at least, suggesting the need for a sustained and consistent AIDS campaigns to influence behavioral changes that will go a long way in reducing the chances of HIV infection. 
http://aps.journals.ac.za

\section{References}

Aggleton, P. 1996. Global Priorities for HIV/AIDS Intervention Research. International Journal of STD and AIDS, 7:13-16.

Allen, S, A. Serufilira, J. Bongaarts et al. 1992a. Confidential HIV Testing and Condom Promotion in Africa: Impact on HIV and Gonorrhea Rates. Journal of the America Medical Association, 268 (23): 3338-3343

Allen, S. J. Tice, P. Van de Pierre et al. 1992b. Effect of Serotesting with Counseling on Condom Use and Seroconversion among HIV Discordant Couples in Africa. British Medical Journal, 304(6842): 1605-1609.

Ankrah, E.M. and Rwabukwali, CB. 1987. Knowledge, Attitude and Practice Study of School Health Education: Implications for AIDS Control. Kampala, Uganda, UNICEF Uganda. 14pp;

Awusabo-Asare, Kofi. 1999. "Obstacles and Challenges to Sexual Behavioral Change" in Resistances to Behavioral Change to Reduce HIV/AIDS Infection in Predominantly Heterosexual Epidemics in Third World Countries, Health Transition Center: Chapter 21: 235-240

Asamoah-Adu, A, S. Weir, M. Pappoe, N et al. 1994. Evaluation of a Targeted AIDS Prevention Intervention to Increase Condom Use among Prostitutes in Ghana. AIDS 8(2): 239-246.

Ayiga, N, Ntozi, JP, Ahimbisibwe, FE et al. 1999. “Deaths, Testing and Sexual Behavioral Change And Its Determinants in Northern Uganda", in Resistances to Behavioral Change to Reduce HIV/AIDS Edited by JC Caldwell et al. Canberra, Australian National University, Health Transition Center.

Bunnel, R.E. 1996. "Promoting or paralyzing Behavioral Changes: Understanding Gender and High Levels of Perceived Risk of HIV Infection in South West Uganda", Thesis Held by the Dept of Population and International Health, Harvard School of Public Health, Boston, MA.

Caldwell, J.C.; Caldwell, P, Ankrah, E.M et al. (1993): African Families and AIDS: Context, Reaction and Potential Interventions", Health Transition Review 3 (Supplement): 1-6

Catania , J.A., Kegeles, S.M. and Coates, T.J. 1990. “Towards an Understanding of Risk Behavior: An AIDS Risk Reduction Model (ARRM)", Health Education Quarterly 17 (1): 53-72.

FMOH. 1999. National Sentinel Survey Report 1999. Abuja.

Green, E.C. 2002. "Abstinence, Fidelity and the Contribution of Religious Groups to Reducing HIV Transmission", Presented at the Annual Meeting of the American Public Health Association.

Gupta, G.R and E. Weiss. 1993. Women's Lives and Sex: Implications for AIDS Prevention. Culture, Medicine and Psychiatry 17: 399-412.

Hogsborg, M. and P. Aaby. 1992. Sexual Relations, Use of Condoms and Perceptions of AIDS in an Urban Area of Guinea-Bissau with a High Prevalence of HIV-2. Pp. 203231 in T. Dyson ed., Sexual Behavior and Networking: Anthropological and Socio-cultural Studies on the Transmission of HIV. Liege, Belgium: Editions Deronaus-Ordina

JAAIDS. 2001. Situation Analysis Reports on STD/HIV/AIDS in Nigeria. www.nigeria.aids.org/situation.cfm;

Jato, MN, Calista Simbakalia, John M. Tarasevich et al., 1999. 'The Impact of Multimedia Family Planning Promotion on the Contraceptive Behavior of Women in Tanzania', International Family Planning Perspectives, vol. 25, no. 2 (June), 60-67 
Lindan, CP, Truong, XL, Le, TG et al. , 1997. Rising HIV Infection Rates in Ho Chi herald Emerging AIDS in Epidemic in Vietnam. AIDS, Supplement 1: SS-13

Mann, J, N. Mukamanzi and M.J.M Taranola and T.W. Netter, eds. 1992. AIDS in the World: The Global AIDS Policy Coalition. Cambridge, MA: Harvard University Press

NACA. 2001. HIV/AIDS Emergency Action Plan (HEAP). Abuja

National Research Council. 1996. Preventing and Mitigating AIDS in Sub-Saharan Africa: Research and Data Priorities for the Social and Behavioral Sciences. National Academy Press. Washington DC.

NDHS 1999. Nigeria Demographic and Health Survey 1999. National Population Commission

Ngugi, E. N., J.N Simonsen, M. Bosire, A.R. Ronald, F.A. Plummer, D.W. Cameroun, P.Waiyaki and J.O. Ndinya-Achola. 1988. Prevention of Transmission of HIV in Africa: Effectiveness of Condom Promotion and Health Education among Prostitutes. The Lancet 2 (8616): 887-890

Prochaska, J.O and DiClemente, C.C. 1986. "Towards a Comprehensive Model of Change" in U. Miller, N. Heather (eds.), Treating Addictive Behavior. New York: Plenum Press.

Odimegwu, C. O. 2002. 'The Impact of Multi-Media Campaign on Contraceptive Behavior of Sexually Active Nigerians', Development and Society, Vol. 32 (1):61-75

Olaleye, DO and Bankole, A. 1994. "The Impact of Mass Media Family Planning Promotion on Contraceptive Behavior in Ghana", Population Research and Policy Review, 13(2): 161-177.

Orubuloye, I.O and Oguntimehin, F. 1999. "Death is Pre-Ordained, it Will Come when it is due", in Resistances to Behavioral Change to Reduce HIV/AIDS.. Edited by JC Caldwell et al. Canberra, Australian National University, Health Transition Center.

Parker, RG. 1996a. Empowerment, Community Mobilization and Social Change in the Face of HIV/ AIDS. AIDS 10 Supplement 3:S27-31

Parker, RG. 1996b. A National Media Campaign: Who Makes the Decisions and what Is Really Needed? AIDS Bulletin, 5(2): 14-15.

Pivnick, A. 1993. HIV Infection and the Meaning of Condoms. Culture, Medicine and Psychiatry 17: 431-453.

Rwabukwali, CB. 1991. Sexual Behavior and the Acceptability of Condoms to Ugandan Males. Revised Version of Paper Presented at the Seminar on Male Fertility and Condom Acceptability Research in Sub-Saharan Africa, Kampala, Uganda, June 3-7

Rosenstock, I.M. (1974): "Historical origins of the Health Belief Model", Health Education Monograph, 2: 328-335

Rosenstock, I.M, Stretcher, V.J. and Becker, M.H. (1988): “Social Learning Theory and the Health Belief Model", Health Education Quarterly, 15: 175-183

Rosenstock, I.M; Strecther, V.J and Becker, M.H (1994): “The Health Belief Model and HIV risk behavioral change" in R.J. Diclemente and J.L. Peterson (eds.), Preventing AIDS: Theories and Methods of Behavioral Interventions. New York: Plenum Press: 5-24.

Sobo, E J. 1995. Choosing Unsafe Sex: AIDS-Risk Denial among Disadvantaged Women. Philadelphia: University of Pennsylvania Press.

USAIDS. 2001. HIV in the Developing World: Maps. USAID Washington DC

Uwalaka, E. and Matsuo, H. (2002): Impact of Knowledge, attitude and beliefs about AIDS on Sexual Behavioral Change among College Students in Nigeria: the case of the University of Nigeria, Nsukka", West Africa Review, Vol. 3(2): 1-13 
Vanlandingham, M.J., S. Suprasert, W. Sittitrai and Chayan Vaddhanaphuti (1993): “Two views of Risky Sexual practices among Northern Thai Males: The Health Belief and the theory of Reasoned Action", CSDE Working Papers, 93-09.

Varga, C.A. 1997. 'Sexual Decision-Making and Negotiation in the Midst of AIDS: Youth in Kwazulu-Natal, South Africa', Health Transition Review, Supplement 3 to Volume 7: $45-67$

Williams, E., N. Lamson, S. Efem, S. Weir and P. Lamptey. 1992. 'Implementation of an AIDS Prevention Program among Prostitutes in the Cross River State of Nigeria', AIDS 6(2): 229-230.

World Health Organization. 1992. Effective Approaches to AIDS Prevention: Report of the Meeting, May 26-29, Geneva, Switzerland: World Health Organization Global Programme on AIDS.

Worth, D. 1999. Sexual Decision-Making and AIDS: Why Condom Promotion Is Likely to Fail. Studies in Family Planning, 20, 6:297-307.

\section{Acknowledgement}

The authors are grateful to Gates Foundation for the award to the Harvard School of Public Health, USA with which AIDS Prevention Initiative in Nigeria (APIN) was established. Data for this paper came from one of the funded initiatives. We are also grateful to Michael Reich and the team of Takemi Fellowship program at the Harvard School of Public Health for the logistic support to the corresponding author to conduct the analysis. 